\title{
Ultrafiltration with Self-Generated RO Concentrate Pulse Backwash in a Novel Integrated Seawater Desalination UF-RO System
}

\author{
Han Gu, Anditya Rahardianto, Larry X. Gao, \\ Panagiotis D. Christofides, and Yoram Cohen*
}

Water Technology Research Center, Department of Chemical and Biomolecular Engineering, University of California, Los Angeles, CA 90095-1592, USA

\author{
Submitted to \\ Journal of Membrane Science \\ Original Submission: 4/11/2016 \\ Revision: July 8, 2016
}

*Corresponding author; E-mail addresses: yoram@ucla.edu 


\begin{abstract}
Ultrafiltration as a pretreatment for RO feedwater with enhanced UF backwash, which combines continuous with pulse backwash, was investigated in a novel UF-RO process integration. Direct supply of RO concentrate to the UF module served for UF backwash which was further enhanced with pulse backwash generated using bladder-type hydraulic accumulators. Model analysis of the hydraulic accumulator operation, which was validated via a series of field experiments, demonstrated a capability for accumulator charging directly from the RO concentrate stream within a period of 30-40 s. Moreover, pulse backwash over a short period ( 5 s) which was added to the continuous UF backwash (directly from the RO brine stream), enabled peak UF backwash flux that was up to a factor of 4.2 - 4.6 higher than the normal filtration flux. The above mode of UF operation with multiple consecutive backwash pulses was found to be more effective than with a single pulse, while inline coagulation further increased the UF performance. Relatively long-term field operation (over eight days where) of the UF-RO system with self-adaptive triggering of UF backwash, whereby the number of consecutive pulses increased when a higher membrane fouling resistance was encountered, was highly effective enabling stable UF operation over a wider range of water quality conditions and without the need for chemical cleaning. These encouraging results suggest that direct UF-RO integration with enhanced pulse UF backwash is an effective approach for dead-end UF filtration without sacrificing water productivity.
\end{abstract}

Keywords: Integrated UF-RO system, Seawater Desalination, Pulse Backwash, Ultrafiltration, Self-adaptive backwash 


\section{Introduction}

Reverse Osmosis (RO) desalination is the leading technology for production of potable water from seawater [1-4]. However, RO seawater desalination requires effective RO feed water pretreatment in order to avoid fouling of the RO elements by suspended particulates, biological and organic materials. Fouling of RO element leads to loss of membrane permeability, increased frequency of cleaning and ultimately reduced element longevity [1, 5-7]. In order to alleviate RO element fouling, microfiltration (MF) and ultrafiltration (UF) have been increasingly used for RO feed pretreatment $[1,6,8,9]$. However, both MF and UF need to be optimized in order to reduce the level of irreversible fouling and reduce the frequency of costly MF/UF chemical cleaning and potential system shutdown [10, 11]. In order to mitigate UF/MF membrane fouling, backwashing or back-flushing (i.e. introduce backwash fluid from the filtrate side to the feed/retentate side of the membrane) has been widely used for cleaning MF/UF membranes [1115]. Backwashing disrupts and removes the foulant cake layer of MF/UF membranes via "liftand-sweep” mechanism [16-18]. Typically, MF/UF filtrate water is collected and used as the backwash fluid for backwash over a period of 30s to several minutes depending on the fouling condition. In order for backwash to be effective membrane manufacturers typically recommend backwash flux that is 2-3 times the filtration flux [19].

In contrast with low frequency backwash, high frequency ( 1-300 backwash instances/min) short duration (0.1-4 s) backwash pulses (typically known as "backpulsing”) have been utilized, in particular, to improve filterability of particulate and colloidal suspensions in either crossflow or dead-end filtration [15, 20-24]. Laboratory studies of backpulsing have been reported for polymeric MF/UF polymeric [18, 22, 25] and ceramic and metallic [13, 26-28] membranes, at pressure range of $\sim 21-90 \mathrm{kPa}$ and $\sim 100-600 \mathrm{kPa}$, respectively. It is noted that in high frequency backpulsing, filtrate recovery (or productivity) is generally in the range of 50-93\%. Backpulsing 
has traditionally relied on backwash fluid delivery from a pressurized reservoir [14, 15, 18, 21, $22,29,30]$, as well as with the use of gas-driven pistons to generate a backwash pulse [28, 31, 32]. It is important to recognize that in large-scale RO feed pretreatment, UF/MF operation is carried out primarily in dead-end filtration in order to maximize filtrate recovery. Therefore, high frequency backpulsing for high throughput RO feed pretreatment for which a steady feed flow is needed would represent a significant operational and equipment challenges [33].

Low frequency backwash is the preferred approach in UF/MF pretreatment of RO feedwater $[3,8,9,20]$, and the addition of low frequency ( 2-5 backwash cycles/hr) pulse backwash using hydraulic accumulators has been proposed for improvement of backwash efficiency [34]. It is noted that UF and MF filtration with pulse backwash, actuated with hydraulic accumulators, has been described in the patent literature [35, 36]. The use of hydraulic accumulators has also been reported for pressure stabilization during backwash of microfilters [37]. Hydraulic accumulator typically consist of a gas and liquid chambers separated by a bladder [38, 39], whereby the accumulator is typically charged via a pump that delivers the backwash water from the filtrate product stream [40]. The operational characteristics of such hydraulic accumulators have been analyzed with respect to their application in automobile regenerative braking (energy storage) [38, 39, 41]. Such hydraulic accumulators can in principle be utilized to enhance backwash flux of UF and MF membranes used for RO feedwater pretreatment. Indeed, in a recent seawater desalination study [34], it was shown that UF pretreatment of RO feedwater was improved with the use of pulsed UF backwash. The above was demonstrated in a UF-RO system in which the RO concentrate stream was used directly for UF backwash, thereby eliminating the need for both intermediate storage tanks (for both RO feed and backwash) and UF backwash pump.

The unique configuration of directly integrated UF-RO operation with RO concentrate use for UF backwash is particularly appealing given the ability to ensure essentially $100 \%$ recovery 
on the UF side while also reducing system footprint. Moreover, given the uninterrupted supply of pressurized RO concentrate, UF backwash operation can be enhanced with one or more consecutive backwash pulses using online hydraulic accumulators. However, the feasibility for self-generation of multiple backwash pulses (using the pressurized RO concentrate stream) and backwash effectiveness requires quantification of the hydraulic accumulator operation in the integrated UF-RO system. Accordingly, in the present work a systematic investigation is presented of the operability and effectiveness of UF pulse backwash for seawater desalination using an integrated UF-RO system. In the first phase of the study the operability of hydraulic accumulator was evaluated using an accumulator charging/discharging model, along with a series of field tests with a directly integrated seawater UF/RO desalination system. The above UF pulse backwash analysis served to fine-tune the pulse backwash strategy and assess the benefit of multiple consecutive backwash pulses, while also exploring the benefit of inline coagulation. Subsequently, the benefit of self-adaptive triggering of UF backwash that combines continuous and multiple UF backwash pulses was evaluated over an extended test period.

\section{Experimental}

\subsection{Integrated UF-RO Pulse Backwash System}

Field studies of UF pulsed backwash were conducted using a seawater UF-RO desalination pilot plant consisted of UF and RO skids integrated as shown schematically in Fig. 1 and described in detail elsewhere [34, 42, 43]. Briefly, the plant was designed with water feed capacity of up to $129.1 \mathrm{~m}^{3} /$ day (i.e., 34,116 gal/day) and permeate product water production of up to $45.2 \mathrm{~m}^{3} /$ day at $35 \%$ feed water recovery. The RO unit consisted of three spiral-wound RO elements (Dow Filmtec SW30HRLE-400, The Dow Chemical Company, Midland, MI) each being 8' 'x 40"' (20.3 cm x $101.6 \mathrm{~cm})$ in size, having a surface area of $37 \mathrm{~m}^{2}$ per element. The UF 
system consisted of a skid of three hollow-fiber (inside-out) UF modules (Dizzer 5000+, Inge, Greifenberg, Germany) in parallel. The multi-bore PES (polyethersulfone) hollow fiber UF modules were $182 \mathrm{~cm}$ in length and $22 \mathrm{~cm}$ in diameter having active membrane area of $50 \mathrm{~m}^{2}$ per module and permeability of $7.0 \pm 0.2 \mathrm{~L} / \mathrm{m}^{2} \cdot \mathrm{h} \cdot \mathrm{kPa}$ [44].

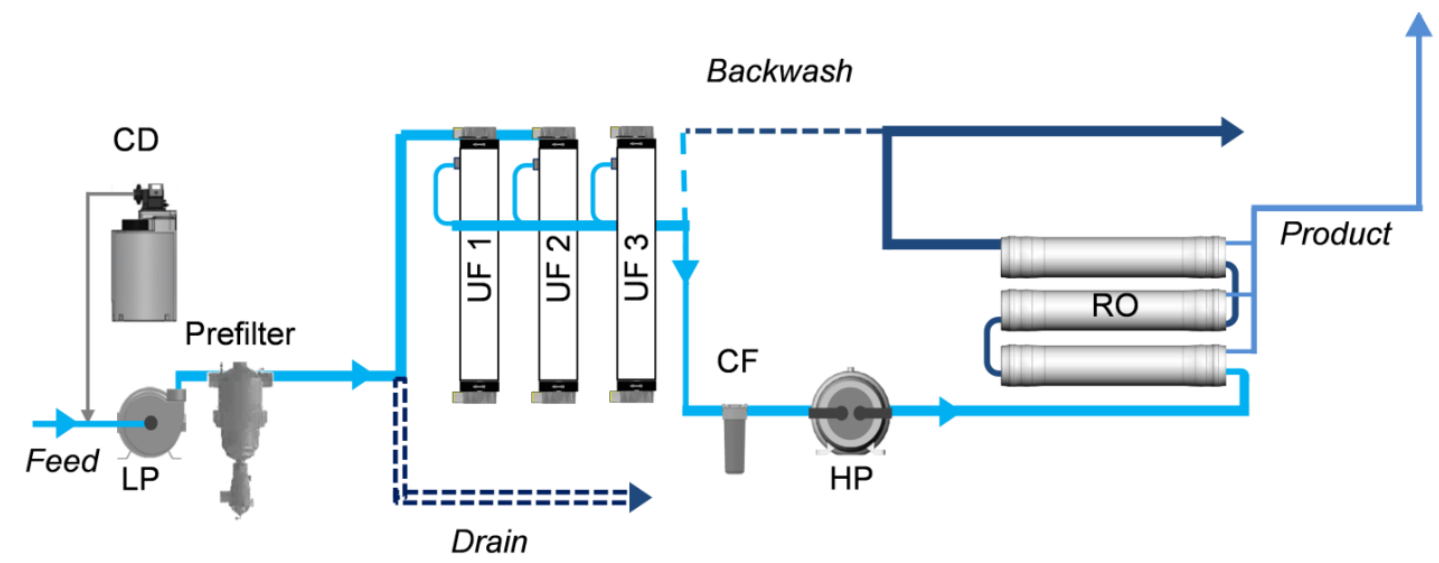

Figure 1. Schematic of the integrated UF-RO system. The MF/UF skid consists of a rotating disk microfilter (prefilter) and three hollow-fiber (inside-out) UF modules connected in parallel. Filtrate stream from the UF modules is fed directly to the RO system. The concentrate stream from the RO system (dashed line) is used directly for UF backwash. (CD: Chemical dosing pump, LP: low pressure pump, HP: high pressure pump, CF: cartridge filter.

The UF unit receives its raw water feed via a centrifugal pump (XT100 SS, 5 hp, Price Pump, Sonoma, CA) equipped with a variable-frequency drive (VFD) (VLT AQUA Drive FC 202, Danfoss, Nordborg, Denmark). Prior to the UF, raw seawater feed is passed through a coarse screen then microfiltered via a self-cleaning screen filter (200 micron, TAF-500E, Amiad Filtration Systems, Mooresville, NC). A metering pump (DDA 7.5-16, Grundfos, Bjerringbro, Denmark) is utilized for coagulant dosing at the inlet of the UF feed pump (Fig. 1). Inline coagulation was accomplished using ferric chloride (Technical grade $\mathrm{FeCl}_{3}, 40.2$ wt\%, Gallade Chemical, Santa Ana, CA). The UF-RO system was equipped with a network of sensors (conductivity, $\mathrm{pH}$, temperature, turbidity, and chlorophyll a), flow meters and pressure 
transducers interfaced with an embedded controller (cRIO-9022, National Instruments, Austin, TX) and data acquisition system.

In the present UF-RO system configuration the UF module automatically responds to flow demand by the RO unit, whereby the pressure and flow rates are controlled as described elsewhere [34]. The concentrate from the RO unit is then used for direct sequential backwash of the UF modules either only through continuous backwash or in conjunction with a pulse backwash making use of two hydraulic accumulators (Fig. 2) each of 3 liters capacity. The RO concentrate stream pressure is throttled down (using a throttle valve) to the level suitable for direct UF backwash and for charging of the hydraulic accumulators (for pulse backwash) with the RO concentrate. The RO concentrate pressure control scheme is described elsewhere [34].

A series of valves (banks of 2 and 3 ways electric actuated ball valves (Type 107, 2-ways, 1.5’', Georg Fischer LLC, Irvine, CA and TEBVA6-1, 3-ways, Plast-O-Matic Valves, Inc. Cedar Grove, NJ) on the UF skid serve for automated switching of UF operation between filtration and backwash modes while maintaining constant productivity for the RO module. Backwash pressure (AST4000 Industrial P Sensor, 0.5\% Acc. 0-517 kPa, American Sensor Technologies, Inc., NJ) and flow rate (Signet Magnetic FM Type 2551, 2", 0-151 L/m, George Fischer Signet, Inc. El Monte, CA) were monitored online during the backwash period.

In the integrated UF-RO system, sequential backwash of the UF modules is accomplished sequentially, whereby as a given UF module is backwashed the remaining two maintain (through filtration at increased flux) the required feed flow to the RO unit. UF backwash is achieved by directing the RO concentrate from the RO modules to the UF backwash line at relatively low pressure (48-50 $\mathrm{kPa}$ ) for continuous backwash (i.e., without a pulse backwash). It is noted that for the present system [34], at its typical RO operational recovery of $\sim 35 \%$, continuous RO backwash flux would be 1.90 times the normal UF operational filtration flux. The above is below 
the typical range of manufacturer recommended backwash flux of $\sim 2-3$ times the filtration flux. Therefore, the system was designed with a capability for pulse backwash in order to elevate the backwash flux and provide for effective UF operation. The above is accomplished in the present system with self-generation of backwash pulse (i.e., charging of the hydraulic accumulators without the use of auxiliary pumps) and flexibility of triggering multiple pulses during a backwash cycle.

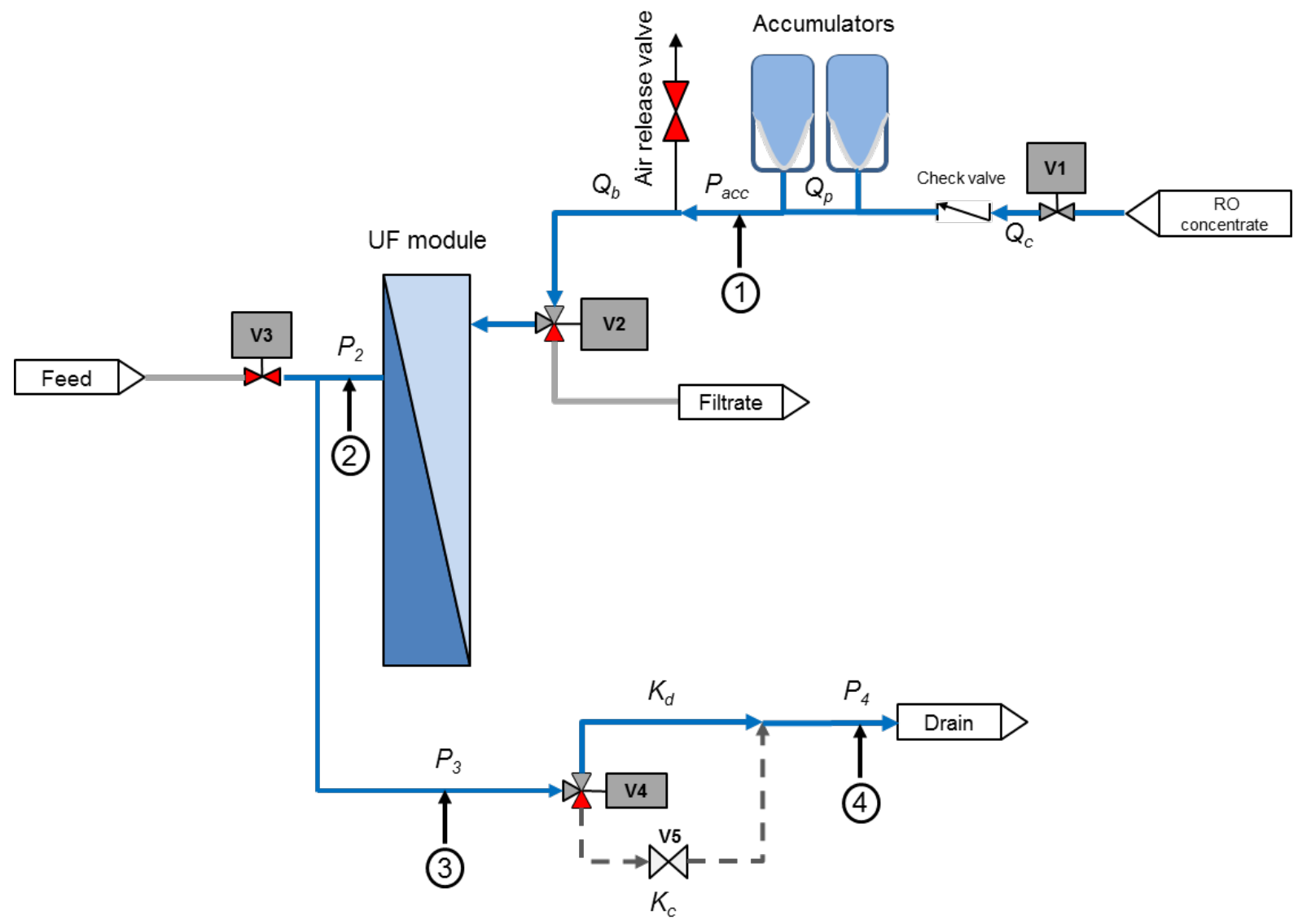

Figure 2. Schematic diagram of the UF pulse backwash (PBW) system (shown for a single UF module). V1: backwash valve, V2: three-way filtrate valve, V3: feed valve, and V4: three-way drain valve. Valves 1-4 are electric actuated ball valves. An adjustable diaphragm valve (V5) serves as a flow regulator in the UF backwash drain line. $Q_{c}$ : RO concentrate flow rate during backwash. $Q_{b}$ : backwash flow rate through the UF module. $Q_{p}$ : flow rate in/out of the accumulators. $K_{c}$ is the flow coefficient for flow segment between locations 3 and 4 (Valve V4 directs the flow via Valve 5 to drain) during accumulator charging; $K_{d}$ is the flow coefficient (for the discharge operation) for the same flow section $(3 \rightarrow 4)$ with valve V4 facilitating direct flow to the drain (bypassing the segment of Valve 5 indicated by the dashed line). 
A pulse backwash cycle involves a charging period during which the three-ways drain valve (V4) is opened to the direction of flow regulator V5 (Type 514 diaphragm valve, 1/2" PVC, Georg Fischer LLC, Irvine, CA) and the accumulators (Sentry C111ND, Blacoh Fluid Control, INC., Riverside, CA) are filled with RO backwash water. During the discharge period, valve V4 is set to divert the RO concentrate flow to drain line (Fig. 2) leading to a rapid (pulse) discharge of the accumulators. The pressure-time profile of the accumulator during charging and discharge is governed by the pressure drop in the flow segment between locations 2 and 4 (Fig 2). The pressure drop (kPa) for the above flow segment was expressed as $\Delta P=\left(Q^{2} / K_{i}^{2}\right) \cdot S G$, where $Q$ $\left(\mathrm{m}^{3} / \mathrm{h}\right)$ is the flow rate, $S G$ is the water specific gravity, and where flow coefficients value during accumulator charging is given as $K_{i}=K_{c}$, and by $K_{i}=K_{d}$ during discharge. The above flow coefficients were determined experimentally from a series of pressure-flow rate measurements for the valve positions set for the above two conditions. These coefficients were essentially constant for the present system and over the range of operating conditions in the study.

In the present system configuration, accumulator charging and discharging can be repeated multiple times during each backwash period. In the present system, the complete backwash cycle (combination of continuous and pulse backwash) was programmed to be autonomous with backwash triggered by a system controller that tracks the UF fouling resistance [34].

Table 1. UF feed water and filtrate quality at the field study location

\begin{tabular}{|c|c|c|}
\hline Water Property & UF feed & UF filtrate \\
\hline Turbidity (NTU) & $1.7-14$ & $<0.02$ \\
\hline TDS (Total Dissolved Solids) $(\mathrm{ppm})$ & $33,440-36,800$ & $33,440-36,800$ \\
\hline Chlorophyll $a(\mu \mathrm{g} / \mathrm{L})$ & $12-400$ & $<0.7$ \\
\hline $\mathrm{pH}$ & $7.5-8.2$ & $7.5-8.2$ \\
\hline Temperature $^{\circ} \mathrm{C}$ & $11.2-19.7$ & $11.2-19.7$ \\
\hline
\end{tabular}




\subsection{Field Study}

The effectiveness of direct UF backwash with RO concentrate and the effectiveness of pulse backwash were evaluated in an integrated UF-RO system at the seawater desalination test facility at the Naval Facilities Engineering and Expeditionary Warfare Center (NAVFAC EXWC) at Port Hueneme, CA. Raw surface ocean water was pumped directly from the port channel through a pumping/distribution facility before delivery to the UF-RO system. The average intake seawater quality is shown in Table 1.

The influence of the charging flow coefficient, $K_{c}$ and RO concentrate flow rate (adjusted by changing the RO recovery at a fixed RO feed flow rate) on charging and discharge fluxes and pressure-time profiles was first evaluated using the accumulator model (Section 3) in a series of short-term field tests. The minimum $K_{c}$ value was 1.86 which assured that the charging pressure did not exceed the manufacturer recommended maximum pressure limit of $480 \mathrm{kPa}$ for the UF module backwash. During pulse backwash (i.e., rapid discharge of the accumulator volume) the flow coefficient $K_{d}$ for the drain flow section (Fig. 2) was 7.80.

UF backwash performance was first evaluated in short-term tests with and without pulse backwash at a fixed backwash frequency, as well as assessing the added improvement of inline coagulant dosing. Subsequently, the effectiveness of pulse backwash that is self-triggered, based on a UF fouling resistance threshold, was demonstrated in a continuous operation over an eight day period. In this latter test, a secondary UF resistance threshold was utilized for initiating a sequence of either 2 or 4 sequential backwash pulses during a given backwash cycle.

\section{Pulse backwash model}

The hydraulic accumulator used in the present system consists of gas and liquid compartments separated by a rubber type bladder [41]. The hydraulic accumulator is charged 
with liquid that is pressurized (from the RO concentrate line, Fig. 2) such that the pressure in the gas chamber $\left(P_{g}\right)$ also increases as its volume $\left(V_{g}\right)$ decreases. The total accumulator volume, $V_{\text {acc }}$, is the sum of the gas $\left(V_{g}\right)$ and liquid $\left(V_{l}\right)$ compartment volumes

$$
V_{\text {acc }}=V_{l}+V_{g}
$$

The gas volume $\left(V_{g}\right)$ can be assumed to follow adiabatic compression/expansion of an ideal gas [45], i.e., $P V_{g}^{\gamma}=\mathrm{C}$, where $\mathrm{C}$ is a constant and $\gamma=C_{p} / C_{v}$ is the ratio of the constant pressure $\left(C_{p}\right)$ and constant volume $\left(C_{v}\right)$ heat capacities, respectively. For ideal gas $\gamma=1$ and for rapid adiabatic expansion $\gamma=1.4$ [45]. The hydraulic accumulator's gas chamber is pre-charged with air and as the liquid compartment is filled with the backwash fluid (i.e., RO concentrate in the present case) $V_{l}$ increases while correspondingly $V_{g}$, decreases while gas chamber pressure increases.

The UF backwash flow rate, $Q_{b}(\mathrm{~L} / \mathrm{min})$ in the integrated RO-UF system (Fig. 2) is given as:

$$
Q_{b}=Q_{c}-Q_{p}
$$

where $Q_{c}(\mathrm{~L} / \mathrm{min})$ and $Q_{p}(\mathrm{~L} / \mathrm{min})$ represent the flow rates of concentrate from the RO module and the liquid flowing into/out of the accumulators during the backwash operation, respectively. $Q_{p}$ can be obtained from the time rate of change of the accumulator liquid volume:

$$
Q_{p}=\frac{d V_{l}}{d t}=\frac{C^{\frac{1}{\gamma}}}{\gamma \cdot P_{a c c}^{\frac{1}{\gamma}+1}} \cdot \frac{d P_{a c c}}{d t}
$$

where $t(\mathrm{~s})$ is time and $P_{a c c}(\mathrm{kPa})$ is the hydraulic pressure at the accumulator outlet (also designated as $P_{1}$ at location 1 in Fig. 2) that can be determined considering the pressure drop over the flow segment between locations 1-2 and 2-4 as indicated on Fig. 2. In the present system the pressure drop between the accumulator and the UF module/valve plus piping segment (Fig. 2, between locations 1 and 4) can be expressed as: 


$$
P_{a c c}-P_{0}=\left(P_{a c c}-P_{2}\right)+\left(P_{2}-P_{3}\right)+\left(P_{3}-P_{4}\right) \square\left(\frac{Q_{b}}{A \cdot L_{p}}\right)+\left(\frac{Q_{b}}{K_{i}}\right)^{2}
$$

where $P_{0}(\mathrm{kPa})$ is the pressure at the UF backwash drain outlet (i.e., location 4, Fig. 2) which is considered at atmospheric pressure. The pressure drop in the piping section between location 2 and 3 (Fig. 2) was relatively small such that $\left(P_{2}-P_{3}\right) /\left(P_{a c c}-P_{2}\right)<0.05$; therefore it is reasonable to approximate the pressure difference $\left(P_{a c c}-P_{0}\right)$ as the sum of the UF module transmembrane pressure $\left(\Delta P_{U F}\right)$ and across UF drain section (between locations 1-2 and 3-4, Fig. 2), respectively. $\Delta P_{U F}$, is related to the UF permeation flux, $J_{U F}=L_{p} \cdot \Delta P_{U F}$, where $L_{p}$ is the average UF membrane permeability during backwash $\left(\mathrm{L} / \mathrm{m}^{2} \cdot \mathrm{h} \cdot \mathrm{kPa}\right)$, and $A$ is the UF module membrane area $\left(\mathrm{m}^{2}\right)$. During accumulator charging, $K_{i}=K_{c}$ and during discharge, $K_{i}=K_{d}$ (Section 2.1) with these coefficients taken as constants when the flow is in the turbulent regime $[45,46]$.

The discharge (or charge) flow rate, $Q_{b}$, can be determined from Eq. (4),

$$
Q_{b}=\frac{\sqrt{1+4 \cdot \alpha \cdot \beta \cdot\left(P_{a c c}-P_{0}\right)}-1}{2 \cdot \alpha}
$$

in which $\alpha=A \cdot L_{p} / K_{i}^{2}$ and $\beta=A \cdot L_{p}$, and where the pressure term, $P_{a c c}$, can be determined from the differential equation obtained by combining Eqs (3) and (5),

$$
\frac{d P_{a c c}}{d t}=Q_{c} \cdot \frac{\gamma \cdot P_{a c c}^{\frac{1}{\gamma}+1}}{C^{\frac{1}{\gamma}}}-\frac{\sqrt{1+4 \cdot \alpha \cdot \beta \cdot\left(P_{a c c}-P_{o}\right)}-1}{2 \cdot \alpha} \cdot \frac{\gamma \cdot P_{a c c}^{\frac{1}{\gamma}+1}}{C^{\frac{1}{\gamma}}}
$$

which can be solved numerically for the pulse back wash charging and discharging periods given the appropriate $K_{i}$ values and the initial condition for the pressure. The maximum attainable charging pressure $P_{\max }$ as determined from Eq. (6) (i.e., by setting $d P_{a c d} d t=0$ ) is:

$$
P_{\max }=\left[\left(2 \cdot Q_{c} \cdot \alpha+1\right)^{2}-1\right] /[4 \cdot \alpha \cdot \beta]
$$

and the maximum discharge flow rate, $Q_{\max }$, is determined by substituting $P_{\max }$ into Eq. (5). 


\section{Results \& Discussion}

\subsection{UF pulse backwash (PBW) pressure and flux profiles}

The pressure and backwash flux profiles for the accumulator charging and discharge cycles are illustrated in Fig. 3 for RO concentrate flowrate of $57 \mathrm{~L} / \mathrm{min}$ and flow coefficients $K_{c}$ and $K_{d}$ values of 2.31 and 7.8, respectively. As the hydraulic accumulator is charged with the RO concentrate its pressure increases up to the maximum value that is reached within $\sim 35 \mathrm{~s}$. During the accumulator charging period, as the RO concentrate fills the accumulator, the continuous RO concentrate backwash flux decreases somewhat (Eq. 5). In all cases the total pulse discharged volume is equal to the water volume stored in the accumulator by the end of the charging period. However, the maximum attainable pulse backwash flux is higher when the accumulator discharge is carried out at a higher initial discharge pressure (attained for longer charging periods) as depicted in Fig. 3. Reaching a higher accumulator pressure (and thus higher peak pulse backwash flux) requires a longer charging time and thus there is a tradeoff between the desire to increase the backwash flux and the longest required charging period for attaining the maximum pressure. For example, in order to increase the charging pressure from 183 to $233 \mathrm{kPa}$ ( 27\% increase), the charging time had to be raised from $14 \mathrm{~s}$ to $48 \mathrm{~s}$; correspondingly, the maximum attainable pulse backwash flux increases by only $10.8 \%$ upon increasing the maximum accumulator charging pressure by $27 \%$. For the illustration of Fig. 3, the backwash flux was (for a period of 8-9 s) a factor of 2.5-4.6 above the normal module filtration flux which is well within the recommended range (Section 2.1). It is noted that in the above case the peak backwash flux was a factor of 4.2-4.6 above the normal filtration flux. 
a)

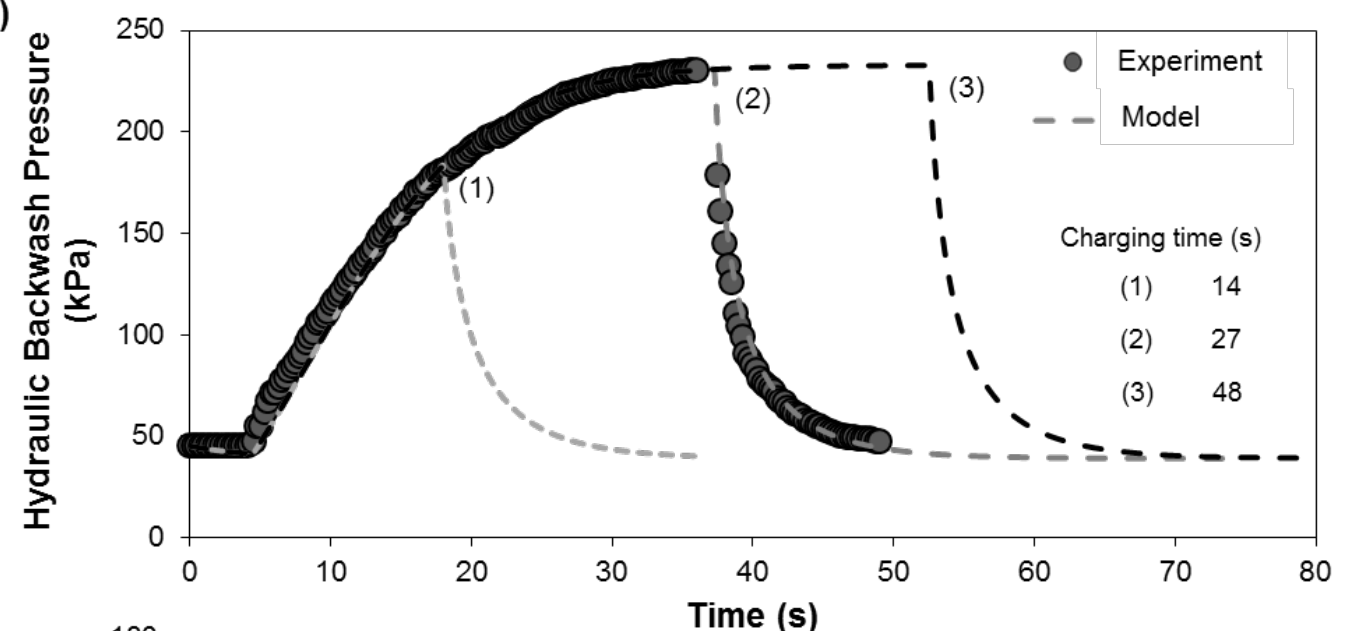

b)

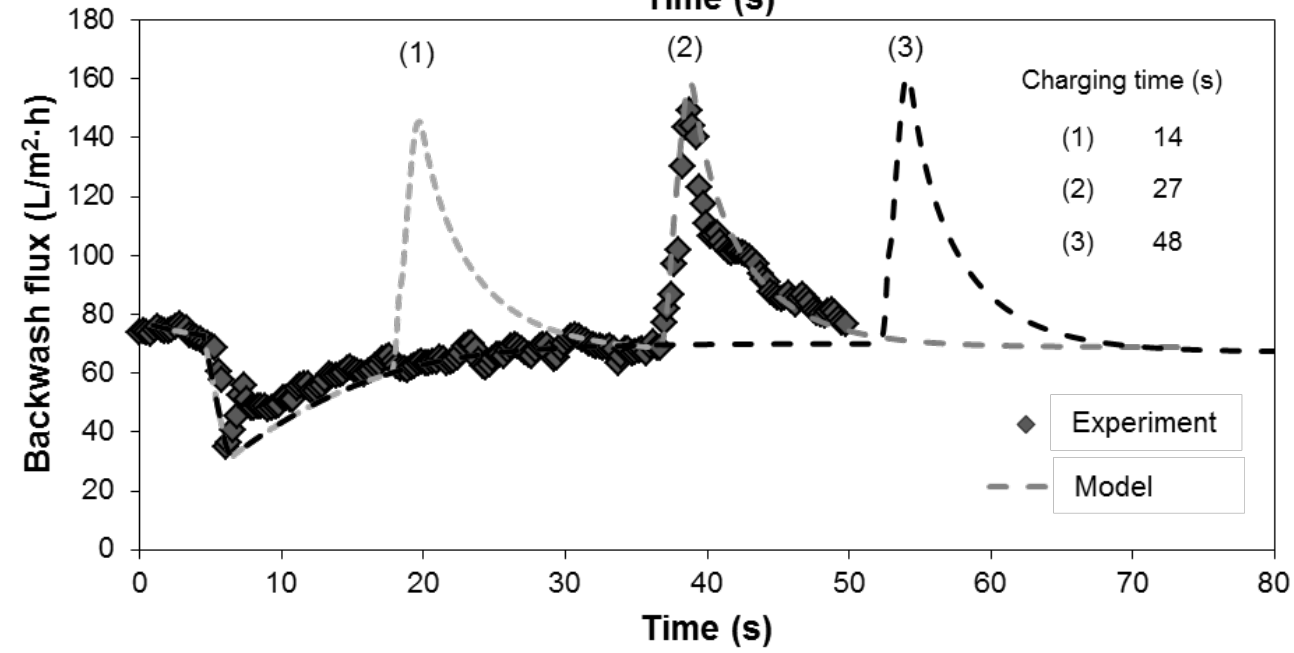

Figure 3. Illustration of the PBW model predictions compared with experimental total backwash flux (continuous and pulse backwash) and accumulator pressure profiles. a) Pressure profiles for the PBW charging and discharging cycle. b) Backwash flux profile for the PBW charging and discharging period. UF single module filtration flux: $34.4 \mathrm{~L} / \mathrm{m}^{2} \cdot \mathrm{h}$. PBW conditions: RO concentrate backwash flowrate: $57 \mathrm{~L} / \mathrm{min}, K_{c}: 2.31, K_{d}: 7.80$. Note: The dashed line depicts the model predicted pressure and flux profiles for charging time of 14, 27 and 48 seconds.

The rate of accumulator pressure increase can be controlled to some degree by adjusting the position of Valve V5 (Fig. 2). For example, restricting the valve opening lowers the flow coefficient $K_{c}$, which then increases the rate of pressure rise leading to a higher maximum attained accumulator pressure. As a consequence a higher pulse backwash flux can be reached. As shown in Fig. 4, as the flow coefficient, $K_{c}$, decreased from a value of 2.64 to 1.86 (i.e. a $29.5 \%$ decrease), for the charging period of 33 s, the attained accumulator pressure increased from 167 
kPa by about 76\% (i.e., to $294 \mathrm{kPa}$ ) with the peak backwash flux increasing by $18 \%$ (i.e., from 151 to $177 \mathrm{~L} / \mathrm{m}^{2} \cdot \mathrm{h}$ ). The accumulator model predictions closely matched the experimental data (Fig. 4) and where the predicted peak flux deviated by 2.21-3.82\% from the experimental values.

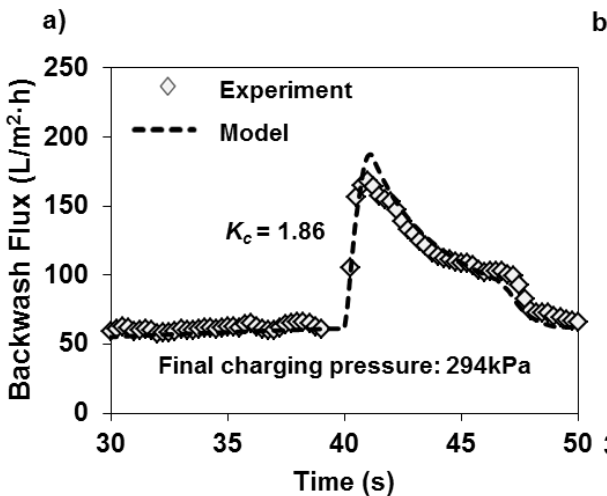

b)

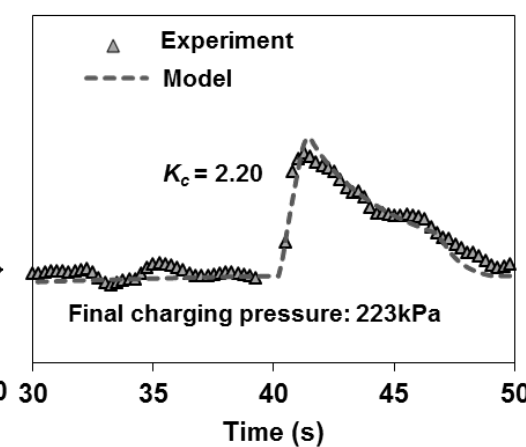

c)

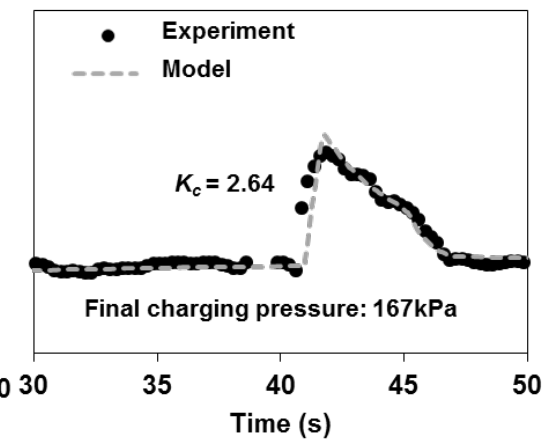

Figure 4. Backwash flux profile attained as an outcome of different conditions of accumulator charging for different values of the flow coefficient $K_{c}$ (Section 3, Eq. 4). Experimental conditions: UF single module filtration flux: $35.0 \mathrm{~L} / \mathrm{m}^{2} \cdot \mathrm{h}$. Pulse backwash condition: RO concentrate backwash flowrate: $57 \mathrm{~L} / \mathrm{min}, K_{d}: 7.80$, Charging time was $33 \mathrm{~s}$.

Higher RO concentrate flow rate $\left(Q_{c}\right)$ would enable higher accumulator pressure and backwash flux to be attained as can be verified from predictions of the accumulator model (Eqs. 6, Section 3; Fig. 5) which closely match the experimental data (Figs. 5 and 6 and Table 2). As an example of the impact of $\mathrm{RO}$ concentrate flow, raising the concentrate flow rate from 58.7 $\mathrm{L} / \mathrm{min}$ by $\sim 30 \%$ (i.e., to $76.5 \mathrm{~L} / \mathrm{min}$; achieved by increasing UF filtration flux for the present system) elevated the final charging pressure (Table 2) from $225 \mathrm{kPa}$ (attained in $37 \mathrm{~s}$ ) to $402 \mathrm{kPa}$ (attained in 32 s), while the peak pulse backwash flux increased by 31.3\% (i.e., from 144.6 to 190.1 L/m² $\cdot \mathrm{h}$ ). Clearly, adjustment of $Q_{c}$ (e.g., diverting part of the RO concentrate to UF backwash) offers additional flexibility in controlling the desirable peak pressure (e.g., to avoid over-pressurizing the UF module during backwash). However, from a practical viewpoint it should be noted that $Q_{c}$ is more likely to be dictated by the target RO system productivity.

For the present integrated UF-RO system with its capability for direct UF backwash with the RO concentrate and its two hydraulic accumulators, the peak backwash flux (i.e., the sum of the 
pulse backwash and the continuous RO concentrate backwash flows) was in the range of $~ 4.2-$ 4.4 times the normal filtration flux which was well within the recommended range (Section 2.1). The use of larger volume accumulators can be useful in attaining a longer backwash pulse, although the peak pulse backwash flux would be unaltered (Fig. 7). Increasing the peak pulse backwash flux can be achieved via control of Valve 5 (Fig. 2), so as to increase the accumulator hydraulic pressure upon being filled with the RO concentrate. For example, in the present system, at the maximum allowable UF operational pressure of $480 \mathrm{kPa}$, the maximum feasible peak backwash flux was about $252 \mathrm{~L} / \mathrm{m}^{2} \cdot \mathrm{h}$ for RO system operation at a feed flow rate of 62.4 $\mathrm{L} / \mathrm{min}$ and at recovery of $35 \%$. Finally, it is noted that operation with consecutive backwash pulses is feasible (Fig. 8; see video in supplementary Information) with a consistent charging period and peak pulse backwash flux.

Table 2. Effect of varying flow coefficient setting of the UF backwash drain line $\left(K_{c}\right)$ and RO concentrate flowrate on peak charging pressure and peak backwash flux

\begin{tabular}{|c|c|c|c|c|c|c|c|}
\hline \multicolumn{8}{|c|}{ Effect of varying flow coefficient setting $\left(K_{c}\right)$} \\
\hline \multirow{2}{*}{$\begin{array}{c}\text { Flow } \\
\text { coefficient } \\
\text { during } \\
\text { charging } K_{c}\end{array}$} & \multirow{2}{*}{$\begin{array}{c}\text { UF } \\
\text { filtration } \\
\text { flux per } \\
\text { module } \\
\left(\mathrm{L} / \mathrm{m}^{2} \cdot \mathrm{h}\right)\end{array}$} & \multirow{2}{*}{$\begin{array}{c}\text { Accumulator } \\
\text { charging } \\
\text { time }\left(\Delta \mathrm{t}_{\mathrm{c}}\right)\end{array}$} & \multirow{2}{*}{$\begin{array}{c}\text { Accumulator } \\
\text { discharge } \\
\text { time }\left(\Delta \mathrm{t}_{\mathrm{d}}\right)\end{array}$} & \multicolumn{2}{|c|}{$\begin{array}{c}\text { Final charging } \\
\text { pressure }^{(\mathrm{c})}(\mathrm{kPa})\end{array}$} & \multicolumn{2}{|c|}{$\begin{array}{l}\text { Peak pulse backwash } \\
\text { flux }\left(\mathrm{L} / \mathrm{m}^{2} \cdot \mathrm{h}\right)\end{array}$} \\
\hline & & & & Theory & Experiment & Theory & Experiment \\
\hline 1.86 & 35.0 & 3 & 10 & 295 & 294 & 18 & 1 \\
\hline 2.20 & 35.0 & 33.0 & 9.5 & 224 & 223 & 16 & 15 \\
\hline 2.64 & 35.0 & 33.5 & 9.8 & 167 & 167 & 157 & 151 \\
\hline \multicolumn{8}{|c|}{ Effect of varying RO concentrate flowrate $\left(Q_{c}\right)$} \\
\hline \multirow{2}{*}{$\begin{array}{c}\mathrm{RO} \\
\text { concentrate } \\
\text { flowrate, } \\
\mathrm{Q}_{\mathrm{c}} \\
(\mathrm{L} / \mathrm{min})^{(\mathrm{b})}\end{array}$} & \multirow{2}{*}{$\begin{array}{c}\text { UF } \\
\text { filtration } \\
\text { flux per } \\
\text { module } \\
\left(\mathrm{L} / \mathrm{m}^{2} \cdot \mathrm{h}\right)\end{array}$} & \multirow{2}{*}{$\begin{array}{l}\text { Accumulator } \\
\text { charging } \\
\text { time }\left(\Delta \mathrm{t}_{\mathrm{c}}\right)\end{array}$} & \multirow{2}{*}{$\begin{array}{c}\text { Accumulator } \\
\text { discharge } \\
\text { time }\left(\Delta \mathrm{t}_{\mathrm{d}}\right)\end{array}$} & \multicolumn{2}{|c|}{$\begin{array}{c}\text { Final charging } \\
\text { pressure }^{(\mathrm{c})}(\mathrm{kPa})\end{array}$} & \multicolumn{2}{|c|}{$\begin{array}{l}\text { Peak pulse backwash } \\
\text { flux }\left(\mathrm{L} / \mathrm{m}^{2} \cdot \mathrm{h}\right)\end{array}$} \\
\hline & & & & Theory & Experiment & Theory & Experiment \\
\hline 57.0 & 32.6 & 32.8 & 12.5 & 227 & 225 & 147.5 & 144.6 \\
\hline 66.0 & 36.2 & 33.0 & 12.5 & 280 & 281 & 168.5 & 165.6 \\
\hline 76.0 & 42.9 & 33.5 & 12.7 & 403 & 402 & 194.9 & 190.1 \\
\hline
\end{tabular}

${ }^{\text {(a) }} K_{c}=2.2$; RO concentrate backwash flowrate: $57 \mathrm{~L} / \mathrm{min}, K_{d}$ : 7.8 ; RO recovery: $34.4 \%$, ${ }^{(\mathrm{b})} \mathrm{RO}$ recovery: $28.8 \%$; ${ }^{(c)}$ gauge pressure. 


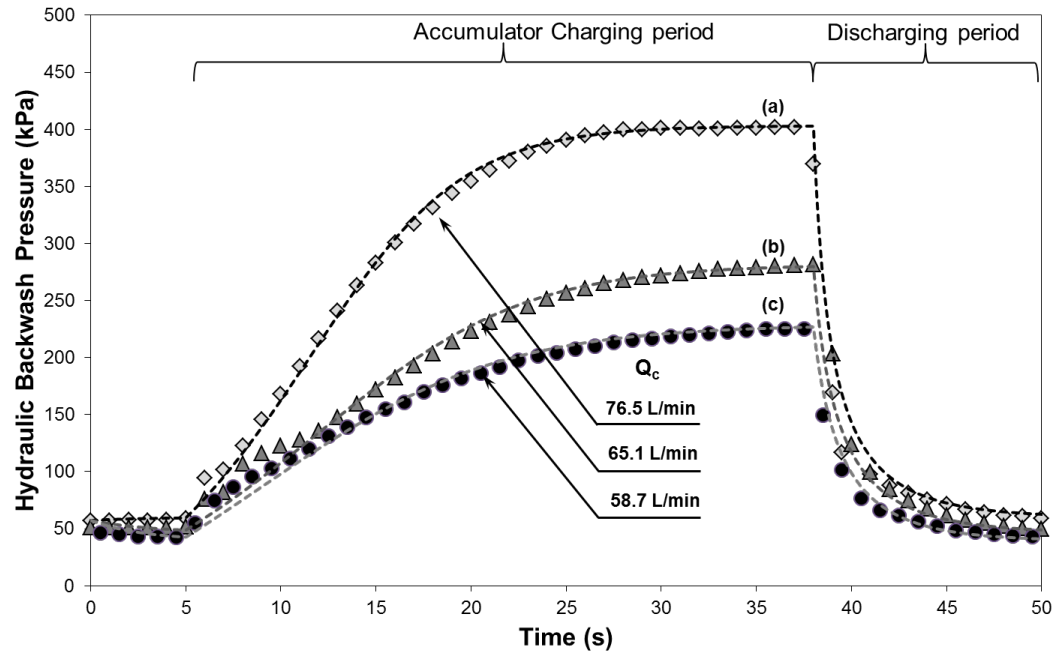

Figure 5. Effect of RO concentrate flowrate on pulse backwash pressure profile. The experimental data and model predictions are represented by filled symbols and dashed lines, respectively. Experimental conditions: $K_{c}: 2.20, K_{d}: 7.80$, charging duration: 30s. Note: The accumulator charging pressure (gauge) prior to discharge were: a) $409 \mathrm{kPa}$; b) $327 \mathrm{kPa}$; and c) $256 \mathrm{kPa}$.

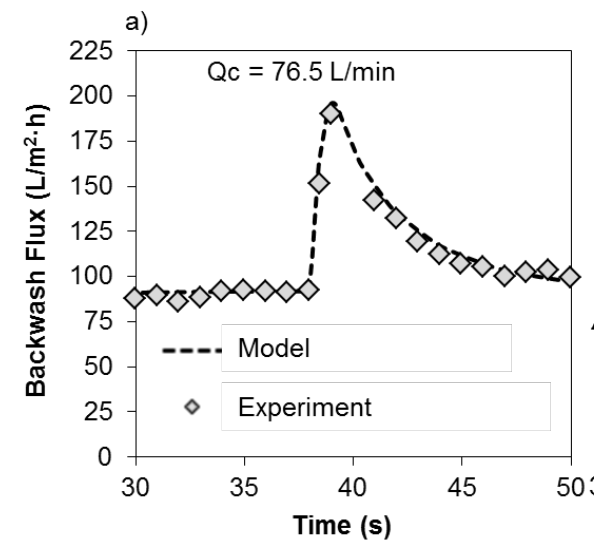

b)

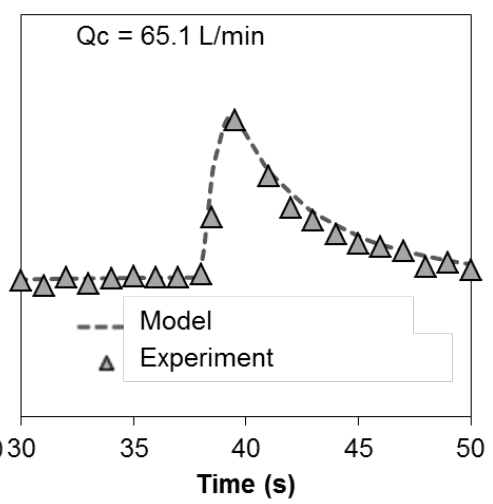

c)

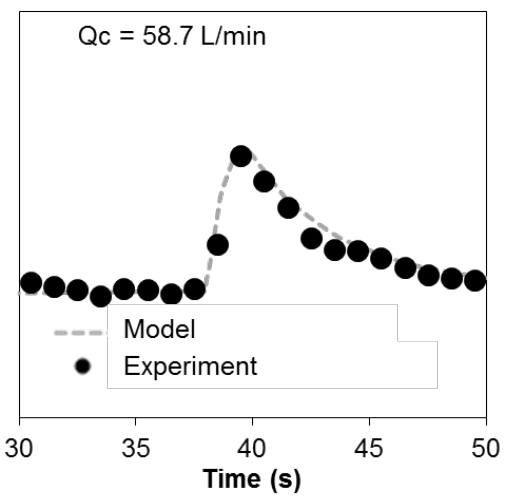

Figure 6. Illustration of the effect of RO concentrate flowrate on pulse backwash flux profile. Experimental conditions: $K_{c}: 2.20, K_{d}: 7.80$, charging duration: 30s. Note: The accumulator charging pressure (gauge) prior to discharge were: a) $409 \mathrm{kPa}$; b) $327 \mathrm{kPa}$; and c) $256 \mathrm{kPa}$. 


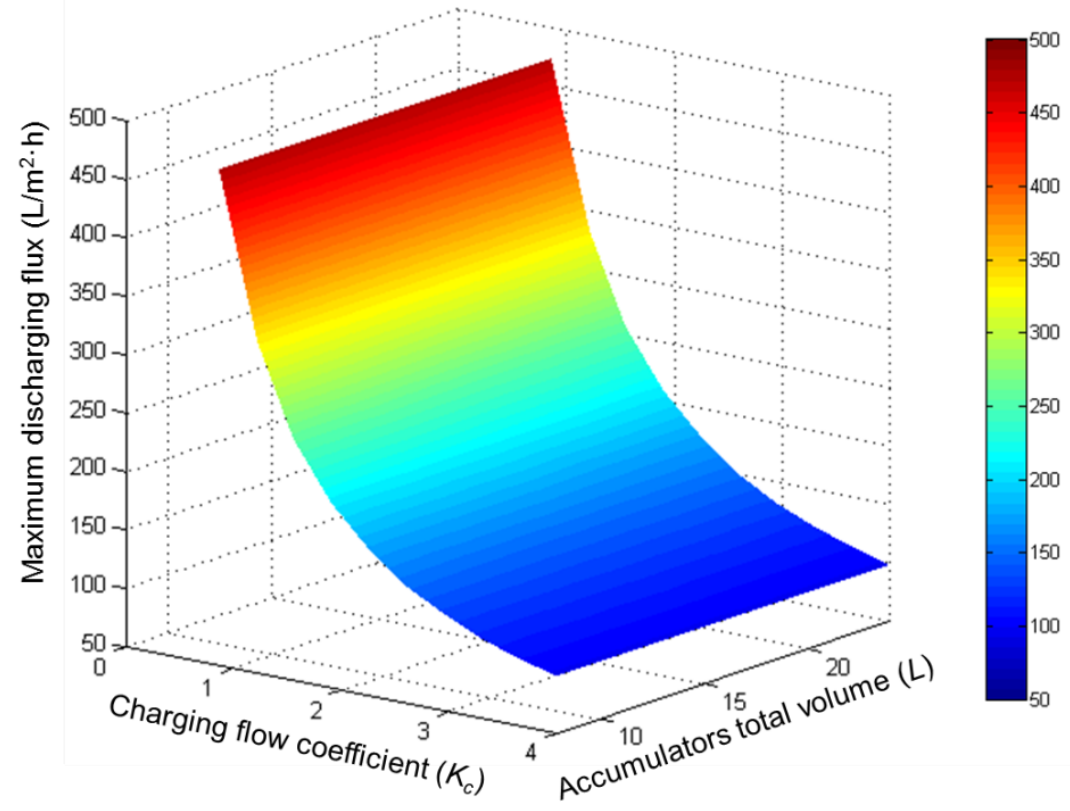

Figure 7. Dependence of peak pulse backwash flux $\left(\mathrm{L} / \mathrm{m}^{2} \cdot \mathrm{h}\right)$ on pulse backwash flow coefficient $\left(K_{c}\right)$ and accumulator volume $(\mathrm{L}) .\left(K_{d}=7.80\right.$, RO concentrate backwash flowrate $\left.=58.3 \mathrm{~L} / \mathrm{min}\right)$.
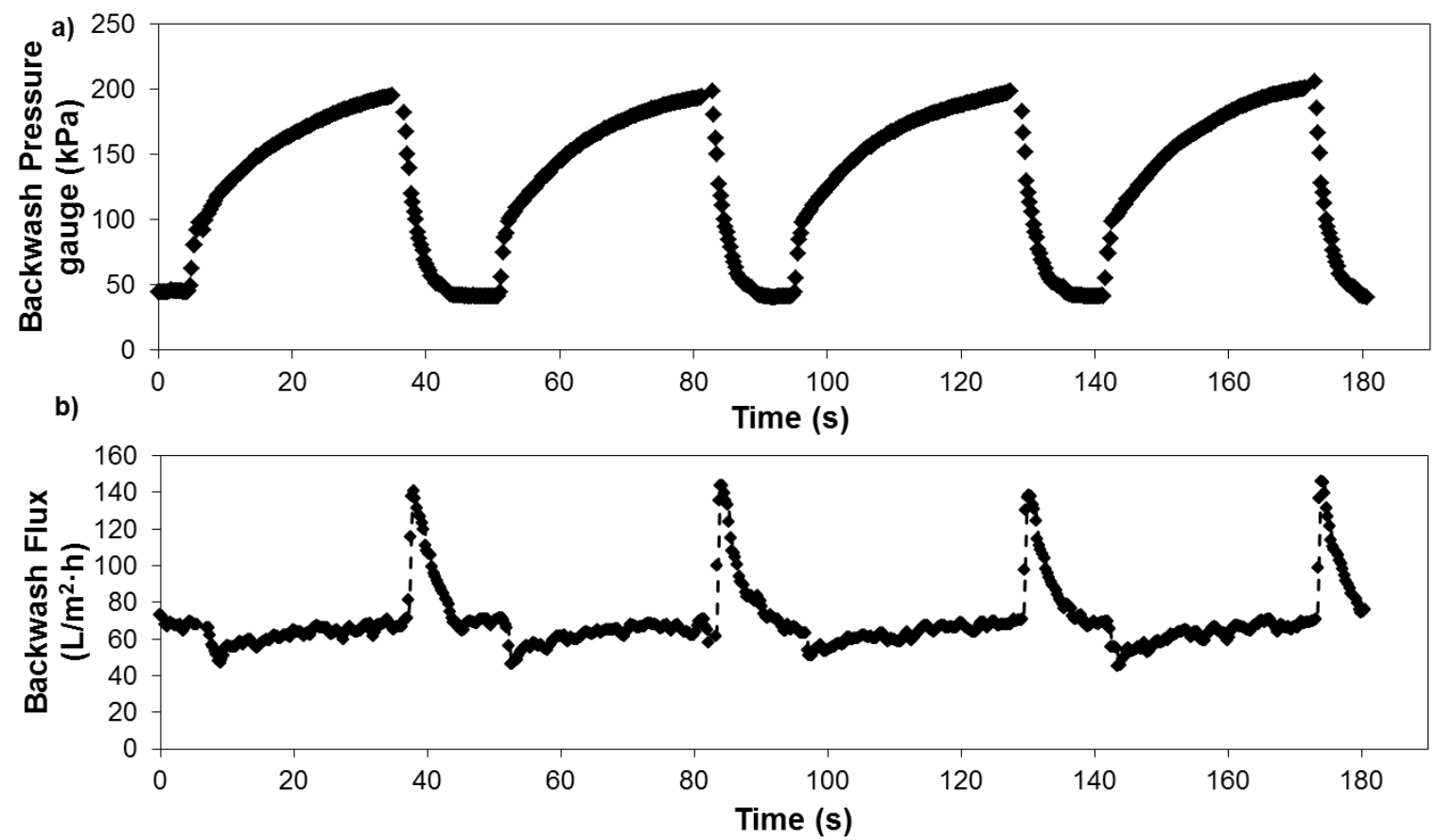

Figure 8. Demonstration of consecutive pulses of UF backwash during a UF backwash period of 180s. a) Backwash accumulator pressure profiles, and b) Backwash flux profile (continuous RO concentrate backwash + accumulator pulse backwash). Flow charging and discharge coefficients were set at $K_{c}=2.21$ and $K_{d}=7.80$ with accumulator charging period of $\sim 35 \mathrm{~s}$ and discharge period of $13 \mathrm{~s}$ for a total backwash period per cycle of $\sim 48 \mathrm{~s}$ and where the continuous RO concentrate backwash flux was $\sim 70 \mathrm{~L} / \mathrm{m}^{2} \cdot \mathrm{h}$. UF system filtration flux per module: $34.4 \mathrm{~L} / \mathrm{m}^{2} \cdot \mathrm{h}$. 


\subsection{Effectiveness of pulse and continuous RO concentrate backwash}

In order to assess the effectiveness of combining continuous RO concentrate backwash with pulse backwash, seawater desalting tests were conducted with the UF-RO pilot under the following conditions: (a) UF operation without coagulation and fixed backwash frequency (every 30 minutes) with continuous RO concentrate backwash flux of $71 \mathrm{~L} / \mathrm{m}^{2} \cdot \mathrm{h}$ for $45 \mathrm{~s}$, followed by two backwash pulses yielding a peak backwash flux of $141 \mathrm{~L} / \mathrm{m}^{2} \cdot \mathrm{h}$; (b) UF operation with inline coagulation (4.01 mg/L Fe ${ }^{3+}$, [34]) and backwash strategy as above, but with a single backwash pulse yielding a peak backwash flux of $141 \mathrm{~L} / \mathrm{m}^{2} \cdot \mathrm{h}$; and (c) UF operation and backwash scheme as in (b) but with two consecutive backwash pulses (each providing peak backwash flux of 142 $\mathrm{L} / \mathrm{m}^{2} \cdot \mathrm{h}$ ) in each backwash cycle. In these tests the normalized UF membrane resistance at the beginning of each filtration cycle was expressed as $R_{U F, i}=\left(R_{i}-R_{o}\right) / R_{o}$, where $R_{i}$ is the overall membrane resistance at the beginning of the ith filtration cycle (just after backwash), and $R_{o}$ is the membrane resistance at the beginning of the filtration test period. Results of the above three tests as depicted in Fig. 9 demonstrate that UF operation without coagulation is less effective even when using two backwash pulses relative to a single one. The rate of fouling in case (a) without coagulation is a about a factor of 3.5 higher than for case (b) with coagulation and only one backwash pulse per backwash cycle. However, when using two consecutive pulses in case (c) instead of a single one as in operation (b), the rate of fouling was lowered by about a factor of 2.4, even though the feed water turbidity was $40 \%$ higher (i.e., $2.20 \pm 0.64$ NTU) than during the former two tests. 


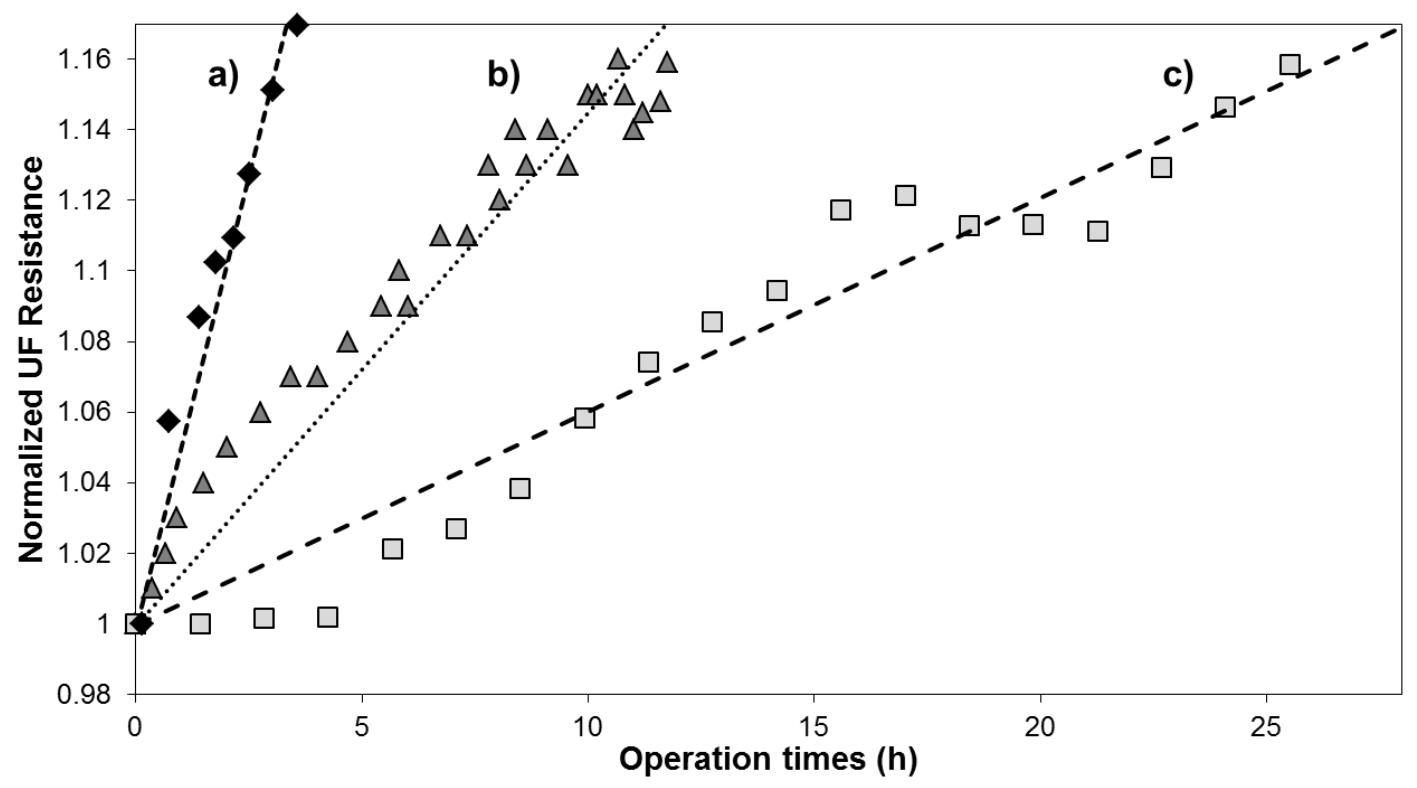

Figure 9. Comparison of the progression of UF fouling resistance for the following UF operation and backwash strategies: (a) UF filtration without coagulation with backwash triggered every 30 min with a continuous RO concentrate backwash $\left(71 \mathrm{~L} / \mathrm{m}^{2} \cdot \mathrm{h}\right)$ for a period of $45 \mathrm{~s}$, followed by two backwash pulses each yielding a peak backwash flux of $141 \mathrm{~L} / \mathrm{m}^{2} \cdot \mathrm{h}$. Raw feed water turbidity $=1.56 \pm 0.42 \mathrm{NTU}$; (b) UF with inline coagulation (dose: $\mathrm{Fe}^{3+}$ : $4.01 \mathrm{mg} / \mathrm{L}$ ) with backwash triggered as in (i) with continuous backwash followed by a single backwash pulse of peak flux of $141 \mathrm{~L} / \mathrm{m}^{2} \cdot \mathrm{h}$. UF feed water turbidity: $1.46 \pm 0.19 \mathrm{NTU}$ ); and (c) UF filtration as in (ii) with a continuous backwash period that is followed by two consecutive backwash pulses each yielding a peak backwash flux of $142 \mathrm{~L} / \mathrm{m}^{2} \cdot \mathrm{h}$. UF feed water turbidity: $2.20 \pm 0.64$ NTU. (Flow charging and discharge coefficients set at $K_{c}=2.21$ and $K_{d}=7.80$, $\mathrm{RO}$ feed flow rate= 86.7 L/min, RO recovery: 35.4\%).

The short-term UF tests (Fig. 9) suggested that the backwash strategy as per test (c) would be beneficial. However, it was also of interest to assess if increasing the number of backwash pulses would increase backwash effectiveness. Accordingly, a self-adaptive UF backwash strategy was utilized whereby UF backwash was triggered when the UF resistance reached a level such that $\Delta R_{U F} / R_{o} \geq \delta$, where $\Delta R_{U F}$ is the maximum allowable UF resistance increase per filtration period, and $R_{O}$ is the initial membrane resistance. Previous studies on self-adaptive UF backwash triggering have indicated that a value of $\delta=0.034$ was adequate for the present UF system [34]. Although a higher $\delta$ value can be set as threshold to enable longer filtration time, such operation 
would in turn require a longer backwash period for effective UF operation. Therefore, there is clearly a tradeoff with respect to triggering backwash and in general setting a backwash trigger such that filtration periods are in the range of $30 \mathrm{~min}$ - $1 \mathrm{hr}$ is regarded as a reasonable approach [3]. Once backwash is triggered, if the UF resistance at the beginning of the given filtration cycles is below a given threshold, i.e., $R_{U F} / R_{o}<\alpha$, then two consecutive pulses are triggered past the continuous backwash period of $45 \mathrm{~s}$. On the other hand, if at the beginning of the filtration cycle $R_{U F} / R_{o} \geq \alpha$ then four consecutive backwash pulses are utilized post the continuous concentrate backwash period. The above filtration and backwash strategy, with $\alpha=$ 1.11, was evaluated over a period of about 8 days (Fig. 10) during which the raw seawater turbidity and chlorophyll $a$ were in the range of $1.75-5.21$ NTUs and $31-121 \mu \mathrm{g} / \mathrm{L}$, respectively. While there was no apparent correlation with the UF resistance-time profile, it is accepted that UF fouling is likely to be impacted by multiplicity of water quality parameters; hence, the challenge of establishing a UF operational strategy based on multiple water quality metrics. Therefore, in the present approach, UF backwash strategy was established based on realtime tracking of the UF resistance. As the field test results indicate (Fig. 10), the UF system fouling rate was high initially but fouling was brought under control despite significant variability of water quality over the course of the field test. Here it is important to note that no attempt was made to optimize the number of backwash pulses. Nonetheless, the results clearly indicates that the combination of continuous backwash with variable backwash pulse frequency can be effective in significantly improving UF operation. 


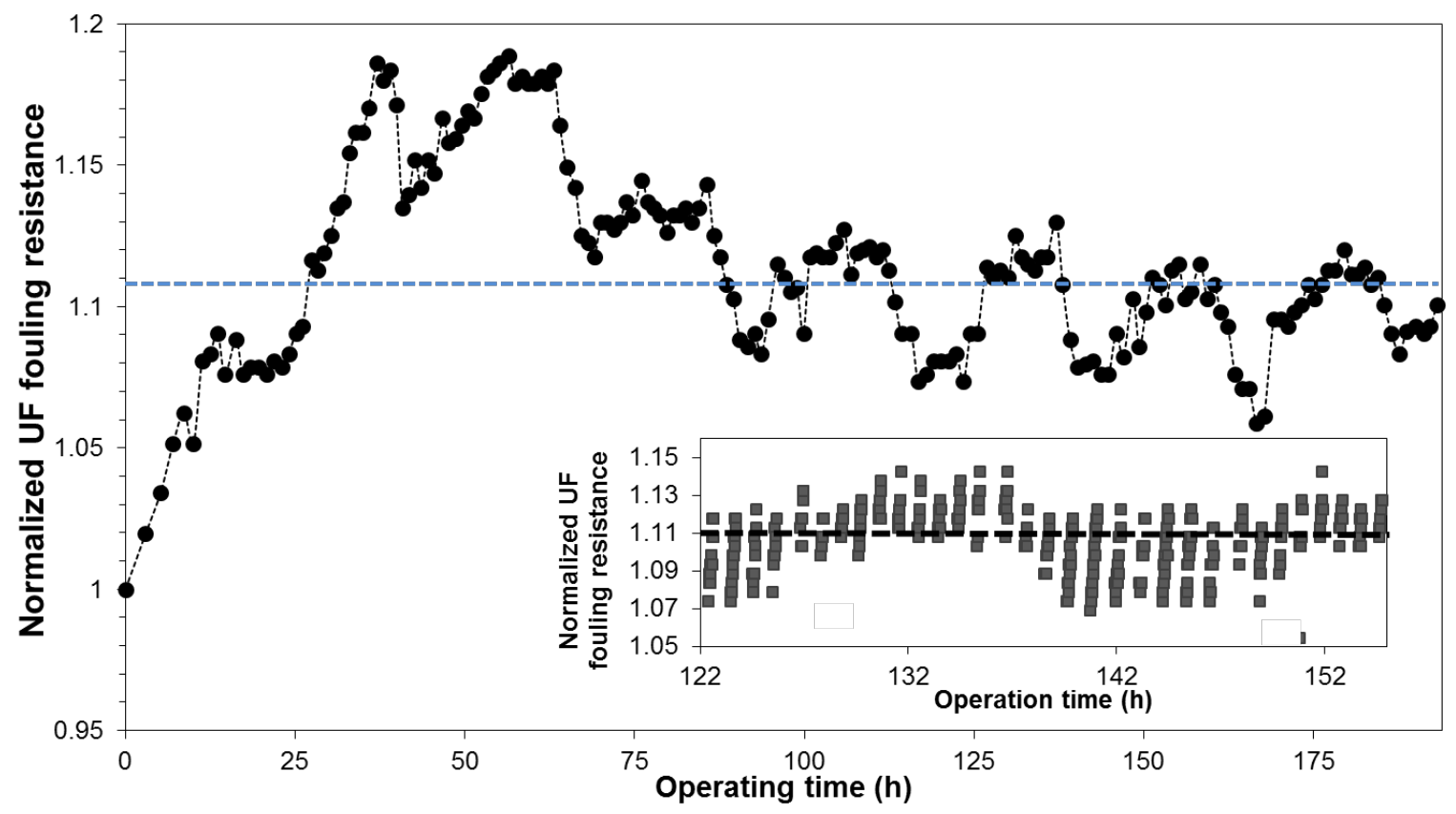

Figure 10. Evolution of UF resistance (normalized with respect to initial UF resistance) during UF operation with coagulation $\left(4.01 \mathrm{mg} / \mathrm{L} \mathrm{Fe}^{3+}\right.$ ) and self-adaptive backwash triggering. Backwash with a continuous RO concentrate flow rate (56 L/min for RO operation at 35.4\%) was for a period of $45 \mathrm{~s}$, followed by either two or four consecutive backwash pulses as determined by a normalized UF resistance threshold (indicated by the dashed line in the main and inset Figures). The inset Figure illustrates a trace of filtration cycles. (UF system filtration flux per module $=34.4 \mathrm{~L} / \mathrm{m}^{2} \cdot \mathrm{h}, K_{c}=2.21, K_{d}=7.80$, charging duration= 35s).

\section{Conclusions}

The integration of continuous UF backwash with direct supply of RO concentrate along with pulse backwash using hydraulic accumulators was evaluated in a novel integrated UF-RO seawater desalination system. Model analysis of the hydraulic accumulator operability, along with experimental validation, demonstrated that direct accumulator charging, with the RO concentrate, to nearly the peak charging pressure can be achieved within a period of 30-40 s. Using the hydraulic accumulators that were self-charged via the pressurized RO concentrate stream, along with continuous delivery of UF backwash of RO concentrate (from the RO unit), enabled peak UF backwash flux that was up to a factor of 4.2 - 4.6 higher than the normal 
filtration flux. UF operation that combines direct continuous RO concentrate backwash with multiple consecutive backwash pulses was found to be more effective than with a single pulse, while inline coagulation further increased the UF performance. Self-adaptive triggering of UF backwash, whereby the number of consecutive pulses increased when a higher membrane fouling resistance was reached, was shown to be highly effective and enable stable UF operation over significant period over a wider range of water quality conditions and without the need for chemical cleaning. The present results suggest that with the present UF-RO integration enhanced UF backwash can be achieved without sacrificing water productivity given the use of RO concentrate for backwash and the flexibility of triggering multiple consecutive backwash pulses.

\section{Acknowledgements}

This work was funded, in part, through grants by the United States Office of Naval Research (N00014-11-1-0950 ONR and ONR N00014-09-1-1132), the California Department of Water Resources (46-4120 and RD-2006-09), U.S. Bureau of Reclamation (R13AC80025), Naval Facilities Engineering Command (N62583-11-C-0630), and the UCLA Water Technology Research (WaTeR) Center. The authors acknowledge the contributions of Dr. Richard Zhu, Dr. Alex Bartman, and John Thompson in the construction of the pilot system. Also acknowledged are the contributions of equipment and materials by Danfoss Sea Recovery (Henrik Wendelboe and Christopher Okada), Inge GmbH (Peter Berg, Martin Heijnen, and Josef Wunram), George Fisher (Rick Hines), Dow Water \& Process Solutions (Michael Kim), and Ahlstrom (Rod Komlenic and Denise Russell) toward construction of the UF-RO plant. The personnel of the Naval Facilities Engineering and Expeditionary Warfare Center (NAVFAC EXWC) at Port Hueneme, CA, namely, William Varnava, Mark Miller, Paul Giuffrida, Theresa Hoffard, Joseph Saenz, and Micah Ing are also acknowledged for their technical assistance during the field study. 


\section{Reference}

[1] A.D. Khawaji, I.K. Kutubkhanah, J.-M. Wie, Advances in seawater desalination technologies, Desalination, 221 (2008) 47-69.

[2] M. Elimelech, W.A. Phillip, The Future of Seawater Desalination: Energy, Technology, and the Environment, Science, 333 (2011) 712-717.

[3] I. Koyuncu, R. Sengur, T. Turken, S. Guclu, M.E. Pasaoglu, 3 - Advances in water treatment by microfiltration, ultrafiltration, and nanofiltration, in: A. Basile, A.C.K. Rastogi (Eds.) Advances in Membrane Technologies for Water Treatment, Woodhead Publishing, Oxford, 2015, pp. 83-128.

[4] C.A. Quist-Jensen, F. Macedonio, E. Drioli, Membrane technology for water production in agriculture: Desalination and wastewater reuse, Desalination, 364 (2015) 17-32.

[5] S. Ebrahim, M. Abdel-Jawad, S. Bou-Hamad, M. Safar, Fifteen years of R\&D program in seawater desalination at KISR part I. Pretreatment technologies for RO systems, Desalination, 135 (2001) 141-153.

[6] N. Prihasto, Q.-F. Liu, S.-H. Kim, Pre-treatment strategies for seawater desalination by reverse osmosis system, Desalination, 249 (2009) 308-316.

[7] L. Henthome, B. Boysen, State-of-the-art of reverse osmosis desalination pretreatment, Desalination, 356 (2015) 129-139.

[8] A. Brehant, V. Bonnelye, M. Perez, Comparison of MF/UF pretreatment with conventional filtration prior to RO membranes for surface seawater desalination, Desalination, 144 (2002) 353-360.

[9] D. Gille, W. Czolkoss, Ultrafiltration with multi-bore membranes as seawater pre-treatment, Desalination, 182 (2005) 301-307.

[10] C. Regula, E. Carretier, Y. Wyart, G. Gésan-Guiziou, A. Vincent, D. Boudot, P. Moulin, Chemical cleaning/disinfection and ageing of organic UF membranes: A review, Water Research, 56 (2014) 325-365.

[11] X. Shi, G. Tal, N.P. Hankins, V. Gitis, Fouling and cleaning of ultrafiltration membranes: A review, Journal of Water Process Engineering, 1 (2014) 121-138.

[12] M. Kennedy, S.-M. Kim, I. Mutenyo, L. Broens, J. Schippers, Intermittent crossflushing of hollow fiber ultrafiltration systems, Desalination, 118 (1998) 175-187.

[13] A.E. Pagana, S.D. Sklari, E.S. Kikkinides, V.T. Zaspalis, Microporous ceramic membrane technology for the removal of arsenic and chromium ions from contaminated water, Microporous and Mesoporous Materials, 110 (2008) 150-156.

[14] C.S. Parnham, R.H. Davis, Protein recovery from bacterial cell debris using crossflow microfiltration with backpulsing, Journal of Membrane Science, 118 (1996) 259-268.

[15] V.G.J. Rodgers, R.E. Sparks, Effects of solution properties on polarization redevelopment and flux in pressure pulsed ultrafiltration, Journal of Membrane Science, 78 (1993) 163-180.

[16] R.K. Lalrinsanga, N.B. Bejgam, S. Ganguly, Effect of pressure pulsing on concentration boundary layer over membrane-a numerical investigation, Asia-Pacific Journal of Chemical Engineering, 8 (2013) 519-526.

[17] A. Massé, O. Arab, V. Séchet, P. Jaouen, M. Pontié, N.-E. Sabiri, S. Plantier, Performances of dead-end ultrafiltration of seawater: From the filtration and backwash efficiencies to the membrane fouling mechanisms, Separation and Purification Technology, 156, Part 2 (2015) 512521. 
[18] S. Redkar, V. Kuberkar, R.H. Davis, Modeling of concentration polarization and depolarization with high-frequency backpulsing, Journal of Membrane Science, 121 (1996) 229242.

[19] E. Drioli, A. Criscuoli, F. Macedonio, Membrane-based Desalination: An Integrated Approach (MEDINA), Iwa Publishing, 2011.

[20] N. Hilal, O.O. Ogunbiyi, N.J. Miles, R. Nigmatullin, Methods Employed for Control of Fouling in MF and UF Membranes: A Comprehensive Review, Separation Science and Technology, 40 (2005) 1957-2005.

[21] H. Ma, C.N. Bowman, R.H. Davis, Membrane fouling reduction by backpulsing and surface modification, Journal of Membrane Science, 173 (2000) 191-200.

[22] S.G. Redkar, R.H. Davis, Cross-flow microfiltration with high-frequency reverse filtration, AIChE Journal, 41 (1995) 501-508.

[23] I. Wenten, D. Koenhen, H. Roesink, A. Rasmussen, G. Jonsson, The Backshock Process: A novel backflush technique in microfiltration, Proceedings of Engineering of Membrane Processes, II Environmental Applications, Ciocco, Italy, (1994).

[24] I.G. Wenten, Application of Membrane Processes in Biotechnology, in: Department of Chemical and Biomolecular Engineering, Technical University of Denmark, 1995.

[25] E.P. Jacobs, S.M. Bradshaw, J.P. Botes, V.L. Pillay, Reverse-pressure back-flush in pilot scale, dead-end ultrafiltration of surface water, Journal of Membrane Science, 252 (2005) 51-63.

[26] M. Lee, Z. Wu, K. Li, 2 - Advances in ceramic membranes for water treatment, in: A. Basile, A.C.K. Rastogi (Eds.) Advances in Membrane Technologies for Water Treatment, Woodhead Publishing, Oxford, 2015, pp. 43-82.

[27] U. Rhyner, R. Mai, H. Leibold, S.M.A. Biollaz, Model of back pressure pulses generated by coupled pressure pulse (CPP) technology, Biomass and Bioenergy, 68 (2014) 175-184.

[28] R. Sondhi, R. Bhave, Role of backpulsing in fouling minimization in crossflow filtration with ceramic membranes, Journal of Membrane Science, 186 (2001) 41-52.

[29] W.D. Mores, C.N. Bowman, R.H. Davis, Theoretical and experimental flux maximization by optimization of backpulsing, Journal of Membrane Science, 165 (2000) 225-236.

[30] V.G.J. Rodgers, R.E. Sparks, Effect of transmembrane pressure pulsing on concentration polarization, Journal of Membrane Science, 68 (1992) 149-168.

[31] C.R. Gillham, P.J. Fryer, A.P.M. Hasting, D.I. Wilson, Enhanced cleaning of whey protein soils using pulsed flows, Journal of Food Engineering, 46 (2000) 199-209.

[32] P. Mikulasek, J. Cakl, P. Pospisil, P. Dolecek, The use of flux enhancement methods for high flux cross-flow membrane microfiltration systems, Chemical and biochemical engineering quarterly, 14 (2000) 117-123.

[33] Microfiltration and Ultrafiltration: Principles and Applications, Taylor \& Francis, 1996.

[34] L.X. Gao, A. Rahardianto, H. Gu, P.D. Christofides, Y. Cohen, Novel design and operational control of integrated ultrafiltration - Reverse osmosis system with RO concentrate backwash, Desalination, 382 (2016) 43-52.

[35] D.R. McGowan, Pressurized backflush system US 6562246 B2, 13 May, 2003 in: U.S.P. Office (Ed.), , US, 2003.

[36] T.M. Schneidewend, Point of Use Filtration System with Backwash, Pub. No.: US 2014/0251905 A1, 11 September 2014 in: U.S.P. Office (Ed.), US, 2014.

[37] Z. Shaowu, Z. Jun, H. Jiang, H. Zhijun, Research on the pressure fluctuation of ceramic filter backwash, in: System Science, Engineering Design and Manufacturing Informatization (ICSEM), 2011 International Conference on, 2011, pp. 47-50. 
[38] M. Xu, G. Chen, J. Ni, Y. Liu, Modeling and Analysis of a Semiactive Power-Assisted Unit Based on Hydraulic Accumulator, Advances in Mechanical Engineering, 5 (2013) 894576.

[39] A. Pourmovahed, S. Baum, F. Fronczak, N. Beachley, Experimental evaluation of hydraulic accumulator efficiency with andwithout elastomeric foam, Journal of Propulsion and Power, 4 (1988) 185-192.

[40] D. McGowan, Size Press \& White Water Filtration Using the Pulse Purge ${ }^{\mathrm{TM}}$ Backwash System, in: Annual Meeting-Pulp and Paper Technical Association of Canada, Pulp and Paper Technical Association of Canada; 1999, 2001, pp. A19-A22.

[41] S. Mamèic, M. Bogdevièius, Simulation of dynamic processes in hydraulic accumulators, Transport, 25 (2010) 215-221.

[42] L. Gao, A. Rahardianto, H. Gu, P.D. Christofides, Y. Cohen, Energy-Optimal Control of RO Desalination, Industrial \& Engineering Chemistry Research, 53 (2014) 7409-7420.

[43] Y. Cohen, P.D. Christofides, A. Rahardianto, A.R. Bartman, A. Zhu, H. Gu, L.X. Gao, Apparatus, system and method for integrated filtration and reverse osmosis desalination, in: US Patent Application Publication No. US20140048462 A1, US. Patent App. 13/822622, 2011.

[44] D. Gille, W. Czolkoss, Ultrafiltration with multi-bore membranes as seawater pre-treatment, Desalination, 182 (2005) 301-307.

[45] M. Rabie, Fluid power engineering, McGraw Hill Professional, 2009.

[46] D.A. Pease, J.J. Pippenger, Basic fluid power, Pearson College Division, 1987. 